\title{
Perspectives on Supply Chain Management in the Healthcare Industry
}

\author{
Yongyi Shou \\ School of Management, Zhejiang University, Hangzhou, China \\ yshou@zju.edu.cn
}

Keywords: Supply chain; healthcare management; perspective

\begin{abstract}
In order to address the perspectives of healthcare supply chain management, the current literature was reviewed comprehensively. Major managerial issues were identified and discussed, including healthcare supply chain performance, cost reduction, inventory management, bullwhip effect, quality and security, and supply chain innovation. Some research methods were also discussed. Value chain analysis is valuable to case studies. System dynamics models or other supply chain reference models are useful for systematic analysis. The study also indicates a potential of application of healthcare supply chain management in developing countries.
\end{abstract}

\section{Introduction}

The healthcare industry is of significant importance in both economic development and social welfare in modern economies. Healthcare is traditionally defined as the delivery of treatment and services to people in need of medical attention. The industry's performance is heavily dependent on a complex network of companies working to design, produce, deliver, and manage a wealth of health and medical related products and services. Hence, healthcare management has attracted increasing attentions from both researchers and practitioners.

The supply chain management (SCM) covers the complete scope from supplier of raw materials, through factories and warehouses, to demand in a store for a finished product. Although originating in the manufacturing industry, supply chain management is a concept that is easily applicable in the healthcare industry. However, even large healthcare systems in the United States, big trusts in the United Kingdom, and hospital chains in Germany are smaller than the multinational global manufacturers of medical supplies [1]. It is also the same in China. Hence, it is a real challenge for hospitals to improve their supply chain performance even though they do not have a dominant position in the supply chain.

This paper analyzed the main perspectives of healthcare supply chain management. Different perspectives of healthcare supply chain management are described and discussed. Research methods and tools in the current literature are then summarized.

\section{Perspectives of Healthcare Supply Chain Management}

SCM in hospitals involves the internal chain, including patient care unit, hospital storage, patient, and etc., and the external chain, including vendors, manufacturers, distributors, and etc. Healthcare SCM processes have three types of flows: physical product flow, information flow, and financial flow. The physical product flow manages customized products and services for the treatment of patients and their needs. Information and financial flows are related to supply chain design decisions for effective product flow and improved organizational performance [2]. The healthcare supply chain is illustrated in Fig. 1.

The main concern about healthcare supply chain management is on its performance. Many studies have been carried out on supply chain performance in the manufacturing industry. For healthcare supply chain management, a key measure is patient satisfaction. An empirical study in South Korea showed that customer satisfaction in healthcare industry is positively related to supply chain performance [3]. The author also investigated the impact of B2B e-commerce on the performance of 
healthcare supply chain, and the relationship between external collaboration and customer satisfaction.

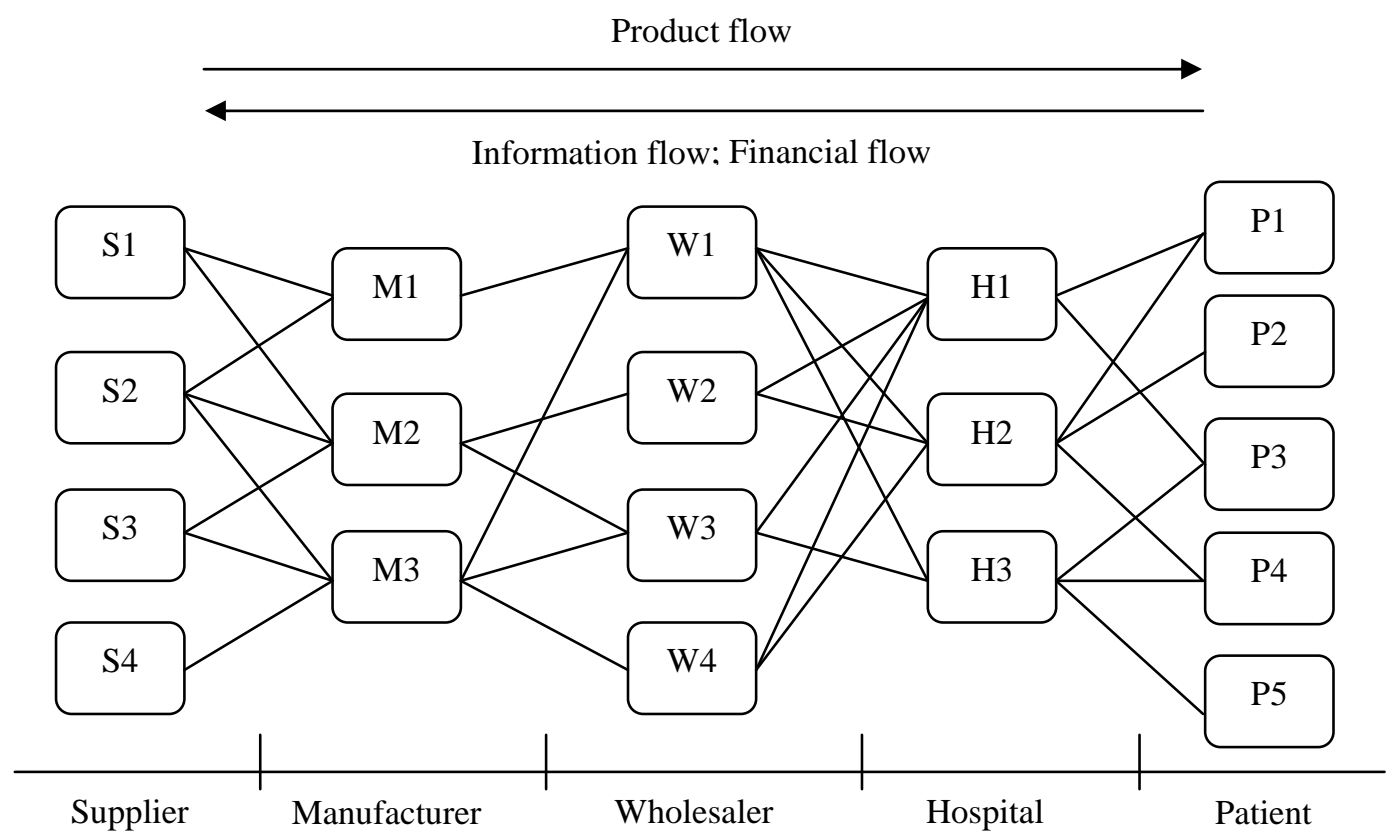

Figure 1. Diagram of a healthcare supply chain

Cost is an important factor of overall healthcare management performance. The healthcare supply chain is in the spotlight as healthcare providers seek to implement cost reduction in this previously untapped resource of financial opportunity. It is estimated that about 25 percent of hospital costs are supply-related [4]. The average integrated delivery network (IDN) with a \$500 million supply budget could save $\$ 12.5$ to $\$ 30$ million by comprehensively redesigning its supply chain [5]. The opportunity costs of healthcare supply chain inefficiency are enormous. With limited hospital budgets, supply chain inefficiencies consume resources that could be used to bring important therapies into more widespread availability.

In many healthcare systems, executives focus on cost containment efforts to lower acquisition price of supplies instead of lowering the total delivered cost [6]. To achieve savings in the healthcare supply chain, healthcare organizations need to cooperate instead of compete. By forming a consolidated service center (CSC), healthcare organizations can centralize their contracting, procurement, distribution, and logistical operations [7]. It is possible to reduce costs without sacrificing quality by process reengineering in healthcare supply chain management [6]. Besides, supply chain finance has been a hot topic recently [8], and a few hospitals including Chinese ones have started to implement supply chain finance.

The inventory in a healthcare supply chain forms a major part of the cost. Managerial tools such as data flow diagram (DFD) can be utilized to analyze the inventory management processes in a hospital [9]. An integrated supply chain management system [10] was proposed for optimizing inventory control and reducing material handling costs of pharmaceutical products in healthcare sector. The vendor managed inventory (VMI) system is able to help hospitals improve the procurement processes and inventory control of pharmaceutical products, which results in decreasing total inventory more than $30 \%$ [10].

A significant problem which may increase healthcare supply chain cost is the bullwhip effect. The "bullwhip effect" (BWE) refers to the phenomenon that order variability increases as orders move upstream along the supply chain [11]. The BWE leads to excess inventory as well as unused or overused capacity. It dramatically increases the operating costs of the supply chain system and often leads to serious supply and demand mismatches and deterioration in customer service levels. So far there are few empirical studies on healthcare supply chain bullwhip effect. System dynamics (SD) 
models have been developed to explain and analyze the bullwhip effect in the healthcare service supply chain $[12,13]$.

Quality is another important measure of healthcare supply chain performance besides cost. Due to the specialty of healthcare service, quality is even more important if security is regarded as one dimension of quality. Quality assurance, such as lot integrity and tracking, is a crucial healthcare supply chain function [4]. It ensures that patients receive safe therapies, and that problems are contained and minimized. Supply chain integrity is a key problem especially in developing countries. Regulations and auditing systems are necessary for healthcare supply chain quality assurance.

Healthcare supply chain innovation is a rare topic in the current literature. A research model in [2] described the impact of supply chain innovation, supplier cooperation, supply chain efficiency, and quality management (QM) practices on organizational performance. Innovative design of supply chain has a significant impact on selection of and cooperation with excellent suppliers, improved supply chain efficiency, and encouragement of QM practices. It was concluded that to achieve competitive advantage, organizations need innovation for better quality care/services, supply chain efficiency, and customer satisfaction based on care competencies.

\section{Research Methods and Tools}

Supply chain management in the manufacturing industry has been a major research area for the last two decades. However, healthcare supply chain management is still in its early stage. Hence, the majority of related studies have adopted qualitative research methods. Many scholars used the case study approach to investigate the factors of healthcare supply chain performance $[6,9,10]$. A few scholars have conducted questionnaire surveys and adopted quantitative approaches [2,3].

In case studies value chain is an effective tool to analyze the activities and functions in a hospital [14]. Fig. 2 illustrates a value chain framework adapted from [14].

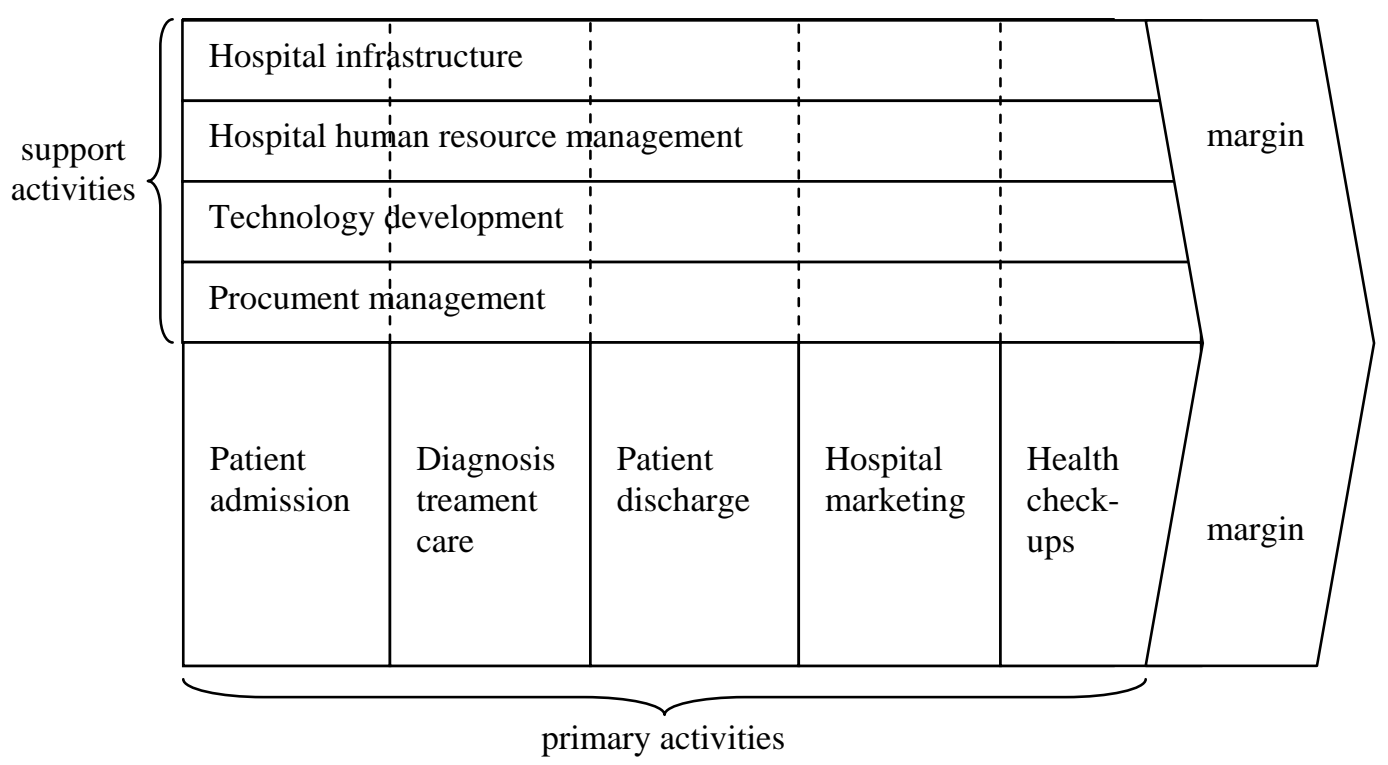

Figure 2. Value chain of a hospital

To analyze the interactions among the healthcare supply chain, well-known models such as Supply Chain Operations Reference (SCOR) and Global Supply Chain Forum (GSCF) models are still useful. However, both SCOR and GSCF frameworks originate in manufacturing and therefore modifications are necessary in applying the approaches to the healthcare industry [1].

Due to the complexity of the healthcare supply chain, system dynamics appears to be applicable modeling method to analyze the interaction among healthcare supply chain members. A few system dynamics models have been proposed in the current literature [12,13].

It is also noted that a meta-analysis of healthcare SCM practices were conducted [15]. Five dimensions of service supply chain management practices, including information and technology 
management, demand management, customer relationship management, supplier relationship management, capacity and resource management, were determined to have significant and positive direct relationship with organizational performance in the public health industry.

\section{Conclusions}

The healthcare industry plays a significant role in modern economies and there are huge potential for healthcare supply chain management to improve its organizational performance. Key issues such as supply chain performance, cost reduction, inventory management, bullwhip effect, quality and security, and supply chain innovation, are addressed in this paper. Different research methods and tools are summarized, including the case study approach, questionnaire survey, system dynamics model, and meta-analysis. Modern supply chain management techniques such as value chain analysis and other supply chain reference models can bring benefits to healthcare supply chains in both developed and developing countries.

\section{Acknowledgments}

This paper is supported by Zhejiang Philosophy and Social Science Planning Project (Grant No. 11ZJQN041YB), and the Fundamental Research Funds for the Central Universities.

\section{References}

[1] U. Hubner, in: eBusiness in Healthcare, Springer, London (2008).

[2] S.M. Lee, D. Lee, M.J. Schniederjans: International Journal of Operations \& Production Management, 31, (2011), pp. 1193-1214.

[3] S.M. Kim, An Empirical Investigation of the Impact of Electronic Commerce on Supply Chain Management: A Study in the Healthcare Industry. University of Nebraska (2004).

[4] J. Byrnes, Fixing the Healthcare Supply Chain. Harvard Business School (2004).

[5] D.C. Roark: Nursing Management, 26, (2005), pp. 36-40.

[6] A. Kumar, L. Ozdamar, C.N. Zhang: Supply Chain Management: An International Journal, 13, (2008), pp. 95-103.

[7] J. Parker, D. DeLay: Healthcare Financial Management, 62, (2008), pp. 66-69.

[8] H. Pfohl, M. Gomm: Logistics Research, 1, (2009), pp. 149-161.

[9] N.H. Mustaffa, A. Potter: Supply Chain Management: An International Journal, 14, (2009), pp. 234-243.

[10] D. Kim: Lecture Notes in Computer Science, 3590, (2005), pp. 218-227.

[11] H.L. Lee, V. Padmanabhan, S. Whang: Management Science, 43, (1997), pp. 546-558.

[12] B. Behzad, Exploring the Bullwhip Effect in a Healthcare Service Supply Chain. Northern Illinois University (2008).

[13] C. Samuel, K. Gonapa, P.K. Chaudhary, et al. International Journal of Health Care Quality Assurance, 23, (2010), pp. 631-642.

[14] V. Gehmlich. in: eBusiness in Healthcare, Springer, London (2008).

[15] L.L. Yap, C.L. Tan: International Journal of Business and Social Science, 3, (2012), pp. 216-224. 